\title{
LOS SUBTERFUGIOS DIGITALES DE JAFAR PANAHI
}

\author{
Bertold Salas Murillo ${ }^{(a)}$
}

JAFAR PANAHI'S DIGITAL SUBTERFUGES

OS SUBTERFÚGIOS DIGITAIS DE JAFAR PANAHI

Fecha de recepción: 20 de octubre del 2018

Fecha de aprobación: 21 de diciembre del 2018

Disponible en línea: 22 de febrero del 2019

\section{Sugerencia de citación:}

Salas Murillo, B. (2019). Los subterfugios digitales de Jafar Panahi. Razón Crítica, 6, 89-111, doi: $10.21789 / 25007807.1448$

(a) Bertold Salas Murillo

Licenciado en Comunicación con énfasis en periodismo y maestro en Artes con énfasis en Cinematografía de la Universidad de Costa Rica

Doctor en Literatura y Artes de la Escena y la Pantalla de la Universidad Laval

Profesor de la Escuela de Estudios Generales y del Posgrado en Artes de la

Universidad de Costa Rica, Costa Rica

https://orcid.org/0000-0003-1624-5320

bertold.salas@ucr.ac.cr 


\section{R E S U M E N}

Dos temas se encuentran en la aplaudida cinematografía de Jafar Panahi (1960): la exposición de las contradicciones de la sociedad iraní y el cuestionamiento del dispositivo cinematográfico. El abordaje de ambas problemáticas ha continuado en la última década, a pesar de la prohibición de dirigir impuesta por los ayatolás. Esto ha sido posible, en gran medida, por las oportunidades que supone la digitalización de las formas de registro y distribución del material audiovisual. En largometrajes como Este no es un filme (2011) y Taxi (2015), Panahi continúa con el examen de las convenciones cinematográficas que comenzó en El espejo (1997), e invita a ver un filme que "se hace solo", es decir un dispositivo que funciona sin la participación de un director o narrador consciente, sino por la simple actividad de un camarógrafo (que no acepta instrucciones) o la operación de un artefacto (la cámara en la cabina del taxi o en el teléfono celular de uno de los pasajeros). De esta manera, Panahi elude la censura gubernamental, al mismo tiempo que hace evidentes ciertos rasgos de la narración audiovisual en el contexto de la digitalización y las nuevas tecnologías.

PALABRAS CLAVE: cine digital, dispositivo, censura, realidad, panahi, cine iraní. 


\section{A B S T R A C T}

Two themes can be found in Jafar Panahi's acclaimed cinematography (1960):

the exposition of contradictions within Iranian society and the questioning of the cinematographic device. Both issues have been continuously addressed in the last decade, despite the prohibition over film directing imposed by the ayatollahs. This has been possible, to a large extent, thanks to the opportunities offered by the digitalization of the recording and the distribution methods of audiovisual material. In films such as This is not a film (2011) and Taxi (2015), Panahi continues with the examination of cinematographic conventions that he began in The Mirror (1997), and invites to see a film that "is made by itself", that is, a device that works without the involvement of a conscious director or narrator, but by the actions of a cameraman (who does not accept instructions) or the operation of an artifact (the camera in the cab of the taxi or in the cell phone of one of the passengers). In this way, Panahi avoids government censorship, while making evident certain features of audiovisual narration in the context of digitalization and new technologies.

KEY WORDS: digital cinema, device, censorship, reality, Panahi, iranian cinema.

\section{R E S U M O}

Dois temas podem ser encontrados na aclamada cinematografia de Jafar Panahi (1960): a exposição das contradições da sociedade iraniana e o questionamento do dispositivo cinematográfico. A abordagem de ambos os problemas continuou na última década, apesar da proibição imposta pelos aiatolás à direção cinematográfica. Isso só foi possível pelas oportunidades envolvidas tanto na digitalização da gravação quanto na distribuição do material audiovisual. Em seus filmes, como Isto não é um filme (2011) e Taxi Teerã (2015), Panahi continua examinando as convenções cinematográficas que começou a analisar em $O$ espelho (1997), convidando-nos a ver um filme que "se faz sozinho", ou seja, um dispositivo que funciona sem a participação de um diretor ou narrador consciente, mas pela atividade simples de um cameraman (que não aceita instruções) ou o funcionamento de um dispositivo (câmera na cabine do táxi ou no telefone celular de um dos passageiros). Dessa forma, Panahi evita a censura do governo, ao mesmo tempo em que evidencia certas características da narração audiovisual no contexto da digitalização e das novas tecnologias.

PALAVRAS-CHAVE: censura, cinema digital, cinema iraniano, dispositivo, Panahi, realidade. 
Taxi, de Jafar Panahi, comienza con un plano general de gente que cruza un paso peatonal. La cámara está situada en el tablero de un coche y, sabrá después el espectador, eso que se ve es Teherán, capital de Irán. Cambia el semáforo, y el automóvil arranca, avanza unos metros y se detiene. El sonido de una puerta que se abre y se cierra llega desde fuera del campo de visión. Se trata de un nuevo pasajero. De inmediato pregunta al conductor por un objeto que tiene al frente: “¿un artefacto antirrobo?”. Lo manipula y lo dirige hacia sí, transformando el cuadro en un primer plano de su rostro, el de un hombre de una treintena de años, quien finalmente devuelve el aparato al tablero, pero esta vez con el visor dirigiéndose al interior del coche, un taxi, en el que se distinguen otros dos pasajeros, una mujer y un hombre. El "artefacto antirrobo" lleva al recién llegado a referirse a los ladrones, quienes según él merecen la pena de muerte; la afirmación suscita la réplica vehemente de la pasajera, y hace que empiece una discusión de la que son mudos testigos el otro pasajero, el conductor y, por supuesto, nosotros, los espectadores. Cuando estos dos clientes han llegado a sus destinos, el pasajero restante pide al chofer no aceptar otros; exclama entonces: “¡lo reconocí, señor Panahi!”. Segundos antes, la edición había cambiado el plano, mostrando el rostro del conductor por vez primera. Con mirada cómplice Omid, nombre del pasajero, dice haberse percatado de que el hombre y la mujer eran actores y que el debate no fue más que una puesta en escena: un director de cine famoso no puede trabajar como chofer. "Es un trabajo como cualquier otro", responde el conductor, quien es, en efecto, Jafar Panahi (1960).

Los reseñados son los primeros once minutos de Taxi, filme realizado por Panahi, y estrenado en el Festival de Berlín del 2015 (en el cual obtuvo el principal premio, el Oso de Oro), a pesar de la prohibición gubernamental de Irán de no rodar durante 20 años, impuesta desde el 2010. Prohibición que el director elude, en alguna medida, como 
en otro de sus largometrajes, titulado ejemplarmente Este no es un filme (Panahi \& Mirtahmasb, 2011), gracias a las características técnicas de las cámaras digitales y al lugar que estas ocupan en el espacio cotidiano contemporáneo. Como en la anterior película, Panahi respeta el mandato estatal en Taxi, dado que no "dirige" nada ni a nadie: simplemente ha colocado dos cámaras en el tablero del coche y ha salido recorrer Teherán como cualquier taxista: que sea la realidad por sí misma y sin la intermediación de un cineasta la que se exprese frente al dispositivo de registro.

En ambas películas, Este no es un filme y Taxi, las apuestas narrativa y audiovisual, consistentes en narraciones supuestamente autónomas, ajenas a las decisiones de un director —o que se presentan como tales-, permiten a Panahi burlar la censura y continuar con los dos ejes que articulan el conjunto de su obra: la radiografía de la sociedad iraní, y el cuestionamiento de los modos de representación a través de la puesta en evidencia del dispositivo cinematográfico. Esto es posible solamente por las transformaciones técnicas y narrativas ligadas a la digitalización de los relatos audiovisuales, como son la portabilidad de las cámaras, las condiciones de almacenamiento de las imágenes y la familiaridad con los relatos fragmentarios, así como por el papel que las cámaras cumplen hoy en la cotidianidad. En las dos películas encontramos dispositivos cinematográficos digitales que entrañan un cuestionamiento de la narración audiovisual, el cual puede relacionarse con el desarrollado anteriormente en El espejo (Panahi, 1997), el segundo largometraje de Panahi, cuya segunda parte se presenta como contada sin que un director tenga un completo control de lo narrado.

Jafar Panahi sitúa lo digital en el centro de sus filmes, y presenta ciertas condiciones y posibilidades que este ofrece a la narración cinematográfica. Examinarlas es el propósito del presente artículo: nos abocamos entonces a la puesta en escena de lo digital en Este no es un filme y Taxi, y cómo esta permite al cineasta, a través de historias que pretenden contarse solas, dar continuidad al abordaje de las contradicciones de la sociedad iraní y al cuestionamiento del dispositivo cinematográfico.

\section{Filmes que se cuentan solos}

Breves sinopsis de Este no es un fllmey Taxi, así como de El espejo, contribuirán a una mejor comprensión del abordaje a desarrollar. El 
primero de estos largometrajes, Este no es un filme, fue grabado después del estreno de los largometrajes El círculo (Panahi, 2000), Sangre y oro (Panahi, 2003) y Fuera de juego (Panahi, 2006), relatos que se constituían a partir de las contradicciones de la sociedad iraní; los tres fueron censurados por el Gobierno y significaron días de cárcel para Panahi, además de que le fue prohibido volver a rodar. Este es justamente el punto de partida de la obra: el director, en condición de arresto domiciliario, convoca a un amigo, el documentalista Mojtaba Mirtahmasb, para "contarle" una película cuyo guion escribió y nunca llegará a realizar. Panahi tiene prohibido dirigir, y la narración postula que no lo hace: ni el director da instrucciones al camarógrafo (y cuando lo hace, este no las sigue), ni lo que muestra la cámara puede ser considerado un filme, mucho menos uno de ficción: se trata simplemente del registro de un tipo que habla por teléfono o a la cámara, o que busca cómo matar el aburrimiento sin salir de su casa. El filme emplea dos cámaras digitales: la de Mirtahmasb y, en la última parte del relato, la del teléfono móvil de Panahi; lo digital también tiene que ver con la difusión del largometraje: copiado en una llave usB y escondido en el equipaje de un amigo de Panahi, este "no filme" eludió la censura y llegó al Festival de Cannes, donde fue presentado en mayo del 2011.

Taxi presenta otro rodeo para eludir la censura: Panahi trabaja como taxista y es como tal que recorre Teherán. Dos cámaras colocadas en el tablero del automóvil registran el ingreso y la salida de toda suerte de pasajeros, quienes describen la idiosincrasia y algunos de los problemas del Irán contemporáneo. Entre los pasajeros se cuenta la sobrina de Panahi, quien porta una pequeña cámara digital pues tiene la asignación escolar de preparar una película "distribuible". Como en Este no es un filme, Panahi no "dirige": se limita a conducir, y es la disposición espacial del automóvil, o los mismos pasajeros (quienes manipulan las dos cámaras del coche, a las que se suman las de la sobrina y del teléfono celular de Panahi, en las manos de Omid), los que determinan qué es registrado por el dispositivo. El filme emplea dos, y quizás tres tipos de cámara digitales: las del coche y de la sobrina (Blackmagic Pocket Cinema Camera, de acuerdo con la ficha técnica del largometraje) y la del teléfono móvil del conductor.

En cuanto a El espejo - apenas el segundo largometraje de Panahi, después de El globo blanco (Panahi, 1995) — , rodado en película de $35 \mathrm{~mm}$, este presenta a una niña, Mina, a quien su madre no recogió a la salida de la escuela. Si bien no recuerda la ruta que debe seguir, decide regresar 
por su cuenta, subiendo y bajando de autobuses que no la llevan a su hogar. Poco antes de la mitad del filme (0:38:45), la niña vuelve la mirada hacia la cámara (es decir, rompe la cuarta pared, y con esta la impresión de realidad) y grita: “¡no actúo más!”. Su aventura no era más que una ficción, y ella no quiere participar más en esta, ante la sorpresa de todo el equipo de producción, en el que se encuentra Jafar Panahi, cerca de dos décadas más joven que el que se verá en Taxi. La chiquilla, quien se llama realmente Mina, decide regresar a casa por su cuenta y abandona el rodaje. Sin embargo, el director no le informa que su ropa aún porta un micrófono, de manera que, sin que la niña se percate, la cámara la sigue durante los siguientes 45 minutos, en un errático recorrido hacia el hogar que semeja el del personaje que representaba en la primera mitad de El espejo.

Los títulos anuncian las lógicas que guían los relatos: El espejo postula la operación especular que será presentada (los diferentes, pero muy semejantes viajes al hogar de Mina, el personaje, y Mina, la "verdadera"), planteando el interrogante sobre si la relación entre la realidad y el registro fílmico es la misma que hay entre una entidad y su reflejo en el espejo. Este no es un filme advierte que la narración en cuestión no es una película, sugiriendo que para serlo se requiere de un director y de un guion. En cuanto a Taxi, otra narración supuestamente sin realizador o libreto, señala la plataforma desde la cual son registrados Teherán y su gente.

Como el lector habrá notado, en los tres filmes, Panahi pone en evidencia el dispositivo cinematográfico, es decir, el conjunto de componentes técnicos, tecnológicos e incluso profesionales que construyen una narración audiovisual: el equipo de producción en $E l$ espejo, el camarógrafo en Este no es un filme, las diferentes en Taxi. En los dos más recientes, Este no es el filme y Taxi, estas herramientas de registro son digitales (los diferentes tipos de cámara, además del disco de memoria, que juega un papel importante en el cierre de Taxi).

En ambas películas, las nuevas tecnologías no solamente hacen posible la narración, como ocurriría en cualquier película rodada en cine digital, sino que coexisten con los personajes (quienes operan cámaras o son conscientes de ser grabados), hacen parte de la diégesis y fijan las posibilidades y los límites del relato.

En Este no es un filme y Taxi, los espectadores somos testigos del funcionamiento de un dispositivo cinematográfico, en este caso digital. La operación nos conduce a dos discusiones, fundamentalmente 
teóricas, que marcaron los estudios fílmicos en los últimos 40 años, las concernientes al dispositivo cinematográfico (principalmente a partir de los años 1970) y la digitalización del cine (comenzando en los años 1990).

\title{
Eso que hace posibles las imágenes
}

La noción de dispositivo cinematográfico puede asociarse, pero no identificarse enteramente, con la de dispositivo, postulada por Michel Foucault, principalmente a propósito de las sociedades de control y de las técnicas de dominio de sí, y afinada por otros filósofos como Gilles Deleuze y Giorgio Agamben. Como explicó en una entrevista, un dispositivo es:

\begin{abstract}
[...] un conjunto heterogéneo, el cual incluye discursos, instituciones, arreglos arquitecturales, decisiones reglamentarias, leyes, medidas administrativas, enunciados científicos, proposiciones filosóficas, morales, filantrópicas; en breve, tanto lo dicho como lo no dicho, esos son los elementos del dispositivo (Foucault, 2001, p. 299) ${ }^{1}$.
\end{abstract}

Esta es la definición foucaultiana. Como advierten François Albera y María Tortajada, esta posee tal amplitud que en la actualidad el término dispositivo "[...] conduce a numerosas definiciones que van del simple mecanismo de un aparato, instrumento o máquina, a la construcción epistemológica capaz de producir efectos de poder o de saber, como el dispositivo disciplinario o de sexualidad" (2011, p. 13) ${ }^{2}$.

Desde los años 1970, y muy probablemente con una inspiración foucaultiana, el término se incorporó a los estudios artísticos, mediáticos y cinematográficos. En esta dimensión más técnica, se le asocia simplemente a un aparataje que posibilita las operaciones de audición y visión, es decir la experiencia del espectador. Sin embargo, incluso detrás de esta caracterización técnica, el dispositivo tiene por función fijar las reglas del juego' y son estas, acuerpadas por sanciones para quienes las rompen, las que revelan el funcionamiento del poder. El dispositivo se

1 “...] un ensemble résolument hétérogène, comportant des discours, des institutions, des aménagements architecturaux, des décisions réglementaires, des lois, des mesures administratives, des énoncés scientifiques, des propositions philosophiques, morales, philanthropiques, bref : du dit, aussi bien que du non-dit, voilà les éléments du dispositif".

2 “[...] renvoie à de nombreuses définitions qui vont du simple mécanisme d'un appareil, instrument ou machine, à la construction épistémologique pouvant produire des effets de pouvoir et de savoir, tel le dispositif disciplinaire ou le dispositif de sexualité". 
sitúa así históricamente, poniendo en contacto una estructura (normas, procedimientos, jerarquías) y una coyuntura; implica la interrelación entre una tecnología, un modo de presentación, una manera de "dirigirse a", una forma fílmica institucionalizada y un posicionamiento de la instancia "espectador" (Kessler, 2003, p. 25).

Valga decir que, sea que se le entienda como un simple aparataje técnico, sea que se le identifique con un régimen de representación, el dispositivo cinematográfico presenta las líneas inventariadas por Gilles Deleuze en su descripción de la noción foucaultiana: "[...] líneas de visibilidad, de enunciación, líneas de fuerzas, líneas de subjetivación, líneas de ruptura, de fisura, de fractura que se entrecruzan y se mezclan mientras unas suscitan otras a través de variaciones o hasta de mutaciones de disposición” (1990, p. 158). El dispositivo cinematográfico genera o interrumpe, posibilita o restringe, narraciones, personajes o contextos, pero también espectadores, y esto hace parte de las reflexiones buscadas por Panahi en El espejo, Este no es un filme y Taxi.

Históricamente, la producción cinematográfica ha contado con un dispositivo en el sentido foucaultiano: el modo de representación institucional (MRI), también denominado clasicismo cinematográfico o cine de Hollywood, pues fue allí donde se gestó principalmente. Se trata de una serie de procedimientos discursivos, concernientes al guion, la construcción de los personajes o el espacio, así como al empleo de la fotografía o la edición, institucionalizados e incluso reglamentados, que se consolidaron desde la segunda mitad del siglo xx y que poseen implicaciones de carácter social, político o moral ${ }^{3}$. Enraizado en los hábitos perceptivos de los espectadores, este MRI tiene entre sus principales características la denominada impresión de realidad, según la cual los relatos que produce son transparentes, es decir, son productos de la realidad y ajenos a la intermediación de una producción discursiva. En los años 1970, el MRI fue uno de los objetivos de la llamada apparatus theory, la cual efectuaba un análisis técnico-ideológico de la representación, en particular de esta impresión de realidad (Albera \& Tortajada, 2011, p. 18).

Podemos mencionar entonces dos acepciones sobre qué es el dispositivo cinematográfico pertinentes en esta investigación: el dispositivo cinematográfico, en singular, es decir el conjunto de

3 Sobre las características del mri: David Bordwell, Janet Staiger y Kristin Thompson (1985) y Jesús González-Requena (2012). 
disposiciones técnicas y prácticas que hacen posible la narración de un filme en específico - como en Este no es un filme y Taxi, pero también en El espejo-, y el "megadispositivo", que supone el MRI, compuesto de estrategias y procedimientos discursivos que han fijado las reglas de infinidad de dispositivos singulares. En este artículo, nos interesa destacar uno de sus principales rasgos: la impresión de realidad a través del ocultamiento del dispositivo. Si bien se le asocia a Hollywood, el MRI se ha instaurado como la lógica narrativa hegemónica, incluso en países geopolíticamente contrarios a los intereses de EE. UU., como Irán después de 1978. Por supuesto, las condiciones materiales, históricas o culturales conducen a que el modo se concrete de manera distinta en cada industria nacional, como sería el caso de la iraní, pero incluso allí se producen películas tan transparentes como las de cineastas aclamados como Majid Majidi o Asghar Farhadi. Sin embargo, para distinguir estas diferentes materializaciones del MRI, este artículo emplea, cuando parece pertinente, el término en plural: modos de representación institucionalizados.

Es este modo de representación el que resulta cuestionado por la cinematografía de Panahi. En los filmes digitales Este no es un filme y Taxi, así como en El espejo, son desenmascarados los procedimientos de producción discursiva del MRI: está constituido por maneras de presentar acontecimientos o temas, construir subjetividad, postular valores estéticos o morales, entre otras operaciones que no solamente se encuentran reglamentadas, sino que, como ya se señaló, se han arraigado históricamente en los hábitos perceptivos de los espectadores. En las dos películas más recientes, Panahi efectúa este desenmascaramiento por medio de dispositivos singulares fundados en las condiciones técnicas de lo digital y el lugar que ocupan las cámaras en la cotidianidad contemporánea.

El hecho de que Panahi no sea el único cineasta iraní que haga uso de herramientas digitales para poner en crisis el sistema de representación del MRI invita a efectuar, en algún otro artículo, un estudio genealógico de la emergencia en la cinematografía del país asiático de estas narrativas divergentes de la impresión de realidad. En el mismo se podrían examinar otras obras à dispositif (para usar el término empleado por Philippe Ortel, el cual es explicado posteriormente), como serían las de Mohsen Makhmalbaf y Abbas Kiarostami. 


\section{La posibilidad digital}

Las premisas de las que parten Este no es un filme y Taxi, esto es, que sean narraciones que se "cuentan solas", pues Panahi respeta la prohibición dirigir; el empleo de las nuevas tecnologías en estos largometrajes, y el pretendido realismo de lo presentado conducen a uno de los más intensos debates de la teoría cinematográfica en los últimos 20 años. En estas dos películas Panahi pone en escena lo digital, su aparente carácter plural, fragmentario y espontáneo, las inusuales dramaturgias y puestas en escena que de este derivan, así como las formas de registro, conservación y transmisión de imágenes y los sonidos (las cuales eran, para el director iraní, prohibidas) que son posibles con las nuevas tecnologías.

Según Kessler, la noción de dispositivo reaparece en la reflexión teórica sobre los medios con la emergencia de las tecnologías digitales, las cuales tocaron no solamente las formas de registro o edición, sino los modos de producción, de distribución y de consumo (2011, p. 25). En los años 1990, principalmente, se discutió de manera ingente lo que suponía la digitalización: para no pocos el cambio de soporte conllevaba la desaparición del cine; para otros, como Jay David Bolter, el cine continuaba su marcha, pese que el soporte fílmico, ese sí, se dirigía a su fin (2005, p. 13). El debate derivaba del hecho de que, como señala Francesco Casetti, el advenimiento de lo digital cambiaba la relación que el cine mantenía con la realidad física desde finales del siglo xix, pues la imagen digital "[...] ofrece una representación de las cosas sin siquiera tener la necesidad de las cosas mismas, gracias simplemente a la elaboración de un algoritmo" (Casetti, 2011, p. 95) ${ }^{4}$.

Brown retoma la posición de D. N. Rodowick, para quien la ontología del cine cambió con el giro digital (digital turn); ahora, eso que era una representación de la realidad causal e indicial (indexical), se convierte en un código matemático que simula la realidad. De esta manera, al ser la imagen digital “[...] infinitamente manipulable y, aún más importante, lucir como real, se destruye nuestra fe en que la imagen pueda ofrecernos la prueba de un tiempo y un lugar existentes" (Brown, 2009, p. 227) ${ }^{5}$. El debate se sitúa ahora "más allá de la indicialidad" (beyond indexicality), pues

\footnotetext{
4 "The digital image has the ability to offer us a representation of things without ever having need of things themselves, thanks simply to the elaboration of an algorithm".

5 "Being infinitely manipulable, and yet (importantly) looking like reality, what has been destroyed is our faith that the image can offer us proof of a time and a place that did exist".
} 
el realismo no depende ya del trazo dejado por los objetos sobre la película sensible. Al respecto, Casetti señala que la realidad ha ocupado siempre una doble posición en la teoría fílmica: como un índice o precondición, en cuanto está vinculada a la fuente de la imagen, y como un efecto de la imagen, el cual surge de cómo esta organiza la representación y se se ofrece al espectador (2011, p. 97). Lo digital subraya esta segunda posición: la impresión de realidad es el efecto de un conjunto de prácticas discursivas que han sido desarrolladas y adquiridas a través de la historia.

Para Casetti, el ocaso de la era fotográfica no implica necesariamente el fin de la actitud realista, pues la "[...] ausencia de un enlace existencial con la realidad empírica — la ausencia de indicialidad- puede ser compensada por la presencia las correctas señales capaces de funcionar como suturas" (Casetti, 2011, p. 96) ${ }^{6}$. Incluso el neorrealismo italiano, que, para Casetti, es la radicalización de este vínculo entre el fotograma cinematográfico y su referente, incluía procedimientos que lo constituían como realista, como la toma larga y la cámara en movimiento, la profundidad de campo, la iluminación espontánea, o deficiente, y el empleo intérpretes no profesionales, entre otros (Casetti, 2011, 98). Por ello resulta interesante - y paradójico- que, pese a su abandono de lo indicial, el cine digital ofrece la facilidad de registro y la proximidad con lo narrado con las que soñaron Vittorio de Sica y Roberto Rossellini, cuyo cine "pobre" se considera un antecedente de muchas películas iraníes. Surgen los interrogantes: ¿cuánto habrían ganado en realismo las obras de los realizadores italianos de haberse empleado tecnologías digitales? ¿No será realismo —o posrealismo- eso que hace Panahi en Taxi?

Esto conduce a una dimensión del cine digital que ha recibido menos atención teórica que la referente a la ontología fílmica: los cambios concernientes la creación. Es allí donde los filmes de Panahi resultan pertinentes, ya que, como señalamos, revelan posibilidades que lo digital abre a la narración cinematográfica. Según Thérèse Giraud, las nuevas tecnologías transforman el acto mismo de filmar; con la pequeña cámara digital:

[... este deviene más libre, más directo, más inmediato, en una palabra: más democrático. No solamente la miniaturización de la

6 "The absence of an existential link with empirical reality — the absence of indexicality — may be compensated for by the presence of proper cues capable of functioning as sutures". 
cámara la pone al alcance de todos sino que, sobre todo, ella permite registrar las situaciones (reales o de ficción), sin interrumpir nada, eso que la pesadez del dispositivo argéntico hacía imposible. Porque es una prolongación del cuerpo del cineasta, porque pasa fácilmente desapercibido, el aparato de registro permite que las personas filmadas aparezcan en la pantalla tan reales y naturales como en la vida (Giraud, 2004, p. 53) ${ }^{7}$.

Se trata de un cine de transparencia radical, en la que el papel del realizador como intermediario de la realidad cambia de naturaleza. En Este no es un filme y Taxi, Panahi parece dejar que la realidad se cuente sola; si algún individuo (también parte de esa realidad) se dirige a una de las muchas cámaras que hoy constituyen el contexto contemporáneo o manipula un artefacto de grabación, esto es también parte de la realidad que se expresa espontáneamente. Giraud retoma el caso de 10 (Kiarostami, 2002), de Abbas Kiarostami, una película que, como Taxi, se desarrolla en el interior de un vehículo y respecto a la que la crítica señaló la desaparición del autor, pues este no imponía su visión de mundo, sino que presentaba la naturaleza humana que se ofrecía a la cámara (2004, p. 56). En Taxi, las cámaras digitales en el tablero presentan un relato ideado no por un director o un guionista, sino por el supuesto azar de los pasajeros que entran y salen del automóvil. Esta lógica narrativa, posible en alguna medida por la digitalización, recuerda lo que propuso el cineojo (Kino glaz) de Dziga Vertov, en un contexto tecnológico diferente: "cine-ojo es igual a cine-grabación de los hechos", resumía el creador y teórico soviético (2010a, p. 32). El cine-ojo "[...] no obliga a la vida que se desarrolle de acuerdo con el guion del escritor, sino que observa y registra la vida tal como es, y solo posteriormente deduce las conclusiones de sus observaciones" (Vertov, 2010b, p. 48).

Entre las "suturas" que construyen el realismo del dispositivo digital se cuentan la fragmentación y la multiplicación de las perspectivas que integran la narración, dada la coexistencia de artefactos de registro, así como la pluralidad de voluntades que los operan. Reflejos de la

7 "Avec la petite caméra numérique, en effet, celui-ci devient plus libre, plus direct, plus immédiat, en un mot : plus démocratique. Non seulement la miniaturisation de la caméra la met à la portée de tous mais surtout elle permet d'enregistrer les situations (réelles ou de fiction) sans rien y déranger, ce que la lourdeur du dispositif argentique rendait impossible. Parce qu'il est un prolongement du corps du cinéaste, parce qu'il passe facilement inaperçu, l'appareil d'enregistrement n'impressionne plus les personnes filmées qui peuvent enfin être à l'écran aussi vraies et naturelles que dans la vie". 
omnipresencia de los dispositivos digitales en el contexto mediático contemporáneo (pantallas, sistemas de vigilancia, teléfonos con cámara). Estas coexistencia y pluralidad condicionan la puesta en escena en las películas de Panahi, como lo demuestra Cronk cuando analiza una secuencia en Taxi, en la que un hombre herido es subido al coche y pide que su última voluntad sea registrada (0:12:45-0:17:00); esto se hace a través del teléfono móvil de Panahi, con el que se registran imágenes que sustituyen las de las cámaras en el tablero. En este pasaje, "[...] múltiples narrativas emergen en medio de los estrechos confines del vehículo, posibilitando una sutil expansión de la infraestructura narrativa" (Cronk, 2015, p. 50 $)^{8}$. La misma polifonía se encuentra en pasajes como esos en los que lo grabado por la sobrina de Panahi con su pequeña cámara sustituye lo que registran las del taxi o, en Este no es un filme, cuando el camarógrafo Mirtahmasb graba a Panahi utilizando la cámara del celular.

Por otra parte, el empleo de lo digital en Este no es un filme y Taxi explicita otro rasgo de los regímenes de visión de la cotidianidad mediática: la vigilancia, ejercida en este caso no por un aparato de control, sino por quien se le opone; si bien es otra la tecnología, encontramos una situación parecida en El espejo. En las tres películas hay operaciones de observación, incluso de voyerismo: en El espejo, Mina es grabada en secreto; en Este no es un filme, Panahi, confinado a su hogar, filma lo que ve por la ventana, como si con la cámara llegara donde su cuerpo no puede; en Taxi, la mayoría de los clientes no son conscientes de estar siendo grabados.

\section{El dispositivo en cuestión}

Cuando Mina mira hacia la cámara y grita “¡no actúo más!”, rompe la impresión de realidad que hasta entonces había construido la narración de El espejo a través de una puesta en escena naturalista, con un uso de la cámara que semejaba el de un documental observacional, actores no profesionales y multitud de detalles cotidianos que funcionaban como suturas (según el término empleado por Casetti) que otorgaban verosimilitud a lo contado. Un efecto semejante tiene la primera oportunidad en que Panahi ve la cámara y sonríe con tristeza en Este no es

8 "[...] multiple narratives converge within the tight confines of the vehicle, enabling a subtle expansion of the film's visual infrastructure". 
un filme (0:11:20), o cuando Omid identifica al director como el chofer en Taxi (0:09:50). Estos tres momentos marcan el comienzo de la puesta en evidencia de los procedimientos discursivos — que es posible caracterizar como de fingimiento o manipulación en función de esta impresión de realidad-, que suelen constituir la narración de los modos de representación institucionales. Esta operación de desvelamiento se efectúa a través de la ejecución de un segundo dispositivo, el cual no solamente cuestiona el primero e instituye una nueva lógica narrativa, sino que, en el caso de Este no es un filme y Taxi, es posible por las facilidades del cine digital y permite la enunciación de una denuncia política.

No está de más dedicar algunas líneas a El espejo, un filme que no parece político, pero cuya radical puesta en evidencia del dispositivo cinematográfico (que incluye al mismo Panahi, en cuanto líder del equipo de producción) pone en crisis la impresión de realidad de la que deriva una parte importante de las repercusiones ideológicas del MRI. El grito de Mina hace opaca una práctica discursiva que se pretende transparente, y revela a los espectadores las decisiones técnicas y formales que están detrás de la narración fílmica. Como explicamos, El espejo se divide en dos partes, separadas por el grito de la niña; cada parte hace entonces uso de dispositivos cinematográficos que, si bien se articulan según lógicas y operaciones distintas, pretenden enunciar la realidad: el primero narra, sin revelar las condiciones de producción discursiva; el segundo, que aparece después del gesto de rebeldía de Mina, también pretende dar cuenta de la realidad, pero mostrando estas condiciones y denunciando (a través de los reclamos de la niña) la falsedad de la primera parte de la película.

Este no es un filme y Taxi hacen uso de un solo dispositivo en cada caso, diferente de los modos de representación institucionales; los dos largometrajes se presentan también como el registro de una realidad sin intermediaciones, en parte por el empleo de cámaras digitales. Se constituyen a partir de precisas reglas respecto al espacio: en Este no es un filme, se trata de cámaras (una operada por Mirtahmasb, la otra por Panahi) en el interior de un apartamento; como el director, quien se encuentra en arresto domiciliario, la cámara no sale de la vivienda, salvo en los últimos minutos, que se desarrollan en el ascensor del edificio donde está confinado. La fijación de las reglas hace parte del relato: Panahi discute con el camarógrafo si el primero puede o no dar instrucciones; posteriormente, marca el espacio de la sala con cinta adhesiva, con el fin de determinar los lugares imaginarios de la película 
que nunca rodó y ahora piensa contar a la cámara. Taxi se desarrolla también en un espacio cerrado, un automóvil, desde el que se ven tanto el interior (Panahi y sus clientes) como una parte del exterior (Teherán). Estos dispositivos suponen algo más que márgenes técnicos: señalan las líneas de lo que es visible o invisible para los espectadores, así como la dramaturgia generada por individuos que se suponen que no son guiados por un guion o un director.

Los tres filmes, pero en particular Taxi, desarrollan lo que Ortel denomina una poética de los dispositivos, en la que las escogencias del cineasta, muchas veces restricciones voluntarias respecto a la puesta en escena, la manera de filmar o la edición, no se limitan a un conjunto de formas preestablecidas (por ejemplo, por un modo de representación institucionalizado), mas, conducen a una exploración de los medios técnicos y de las interacciones humanas (Ortel, 2011, p. 216). En Taxi, el automóvil limita y provoca al mismo tiempo la puesta en escena: el vehículo, en conjunción con las cámaras dispuestas en su interior, modela una visualidad - muy diferente del funcional régimen de visión propio del MRI-, así como las líneas que marcan los intercambios entre los personajes. Del papel del automóvil en la película de Panahi puede decirse lo que Ortel señaló respecto a 10 de Kiarostami: el vehículo, con la integración de múltiples artefactos de registro, es un dispositivo en acción, un agenciamiento que regula las relaciones humanas, favorece el diálogo e intercala la expresión diferentes puntos de vista (2011, p. 215).

Ortel distingue entre relatos narrativos y relatos de dispositivo (los ya citados récits à dispositif). Del primer tipo son las películas que responden al MRI: se desarrollan en función de claros propósitos narrativos e ideológicos, y no rompen con la impresión de realidad, como ocurre incluso en otras películas de Panahi, tales como El globo blanco o Fuera de juego. Relatos de dispositivo son, en cambio, El espejo, Este no es un filme y Taxi: piezas en las que los aparatajes tecnológicos y narrativos se sitúan en un primer plano de visibilidad, y no se esconden bajo la anécdota relatada. Los relatos de dispositivo generan una tensión en los espectadores, pues, cuando un cineasta hace del "efecto-dispositivo" un principio de la narración, "[...] hace casi inoperantes las categorías de análisis elaboradas [...] por la narratología clásica: estas convienen sobre todo a las narraciones 'transitivas', fundadas sobre el encadenamiento 
directo de antes y después, de causas o efectos" (2011, p. 210) ${ }^{9}$. Los relatos de dispositivo, como los tres largometrajes de Panahi, exigen que los espectadores identifiquen la singularidad del nuevo dispositivo propuesto, las inusuales pautas conforme a las cuales la fábula se despliega.

El desvelamiento del dispositivo cinematográfico pasa por hacer opaco lo que se pretende transparente, y pone en evidencia las materialidades que hacen posible su funcionamiento. Esto es posible por el desenmascaramiento de los agentes de enunciación, como ocurre en El espejo, cuando se presenta el equipo de producción y sus deliberaciones ante la protesta de Mina, o en Este no es un filme, cuando Panahi hace preguntas al camarógrafo respecto a los planos o la luz. También por medio de la multiplicación de estos agentes, como ocurre en Este no es un filme, en el que las cámaras son operadas por el camarógrafo o el mismo Panahi, o en Taxi, en el que las tecnologías de registro digital son parte del automóvil o Omid, la sobrina, o el mismo realizador, quien en algún momento mueve las que están en el tablero, las ejecutan. Con esta estrategia la producción discursiva, generalmente invisible para los espectadores, se convierte en parte central del relato.

Por supuesto, al igual que los que se adecúan al MRI y pretenden construir la impresión de realidad, los dispositivos desplegados en Este no es un filme y Taxi producen también un discurso realista a partir del registro digital y supuestamente espontáneo de la realidad. Las suturas de este discurso se vislumbran en los cambios de plano como consecuencia de los movimientos de las cámaras (en manos de algún personaje), de los interrogantes que siembran los personajes (¿actores o individuos que se interpretan a sí mismos?), pero principalmente a través de la edición. Esta última posee una gran importancia en Taxi, puesto que las imágenes provienen de cuatro cámaras, pero en el cuadro solo presenta lo registrado por una cada vez ${ }^{10}$. La diferencia entre el realismo buscado por los dispositivos cinematográficos de estas películas y los que soportan las narraciones del MRI es que en los filmes de Panahi no hay una impresión de realidad convencional: la lógica de enunciación es opaca e invita a su

9 "Quand un cinéaste fait de l'effet-dispositif un principe de narration, il rend quasiment inopérantes les catégories d'analyse élaborées depuis les années 1960 par la narratologie classique : elles conviennent surtout aux narrations «transitives », fondées sur l'enchaînement direct des avants et des après, des causes et des effets".

10 A diferencia de lo que encontramos en una pieza clave en la presentación de las posibilidades narrativas del cine digital: Timecode (2000), del británico Mike Figgis, en la que el cuadro es dividido en cuatro partes, correspondientes a otras tantas tomas que registran acontecimientos simultáneos. 
cuestionamiento. Los dispositivos de Este no es un filmey Taxi no ocultan las contradicciones que los constituyen: si Panahi pretende respetar la prohibición de dirigir, ¿quién decidió la edición?; ¿quién escogió la música de cuerda que acompaña ciertos pasajes de la película del 2015? En la del 2011, ¿quién colocó la cámara frente al director, cuando se presenta la llamada que hace a su amigo camarógrafo, al inicio de la película? Los filmes de Panahi revelan las contradicciones que los filmes clásicos procuran disimular.

\section{La insurrección por el dispositivo}

Panahi pretende continuar haciendo cine, pese a la prohibición impuesta por el régimen de los ayatolás; las nuevas tecnologías se lo permiten, no solo por las facilidades que ofrecen para la producción, sino para la distribución (recordemos cómo llegó Este no es un filme a Cannes). Le interesa, además, seguir con la revisión del dispositivo cinematográfico. Hay entonces en Este no es un filme y Taxi una remediación digital de las operaciones de desenmascaramiento del dispositivo desarrolladas en producciones en celuloide como El espejo, ahora como complemento de una denuncia política. Según Friedlander, el realismo de Este no es un filme constituye una estética política al oponer al régimen estético del poder nuevas configuraciones en torno a lo que puede ser visto (2015, p. 70); desde el título de la obra, el cineasta iraní denuncia la imposibilidad de representar:

Su desafío representacional es doble: se le prohíbe tanto representar (a través del mandato de no hacer filmes) y como ser representado (por la prohibición de hablar a los medios). El filme hábilmente consigue la expresión de esta doble condición de irrepresentabilidad no simplemente por hacer visibles sus circunstancias, sino por poner en crisis el mismo sistema de representación bajo el cual su aprieto es hecho invisible (Friedlander, 2015, p. 77) ${ }^{11}$.

11 "His representational challenge is doubled: he is both banned from representing (through the injunction to not make films) and prevented from being represented (through the prohibition to speak to the media). The film deftly accomplishes the expression of this double condition of unrepresentability not by merely making his circumstances visible, but rather by throwing into crisis the very representational system under which his plight is made invisible". 
La negación del título es más que un comentario metalingüístico: es un recordatorio de la prohibición y de las particulares condiciones de producción. La cámara digital es, desde el comienzo de la narración, parte de la diégesis y, como agrega Friedlander, su intrusión "[...] desestabiliza las afirmaciones de realismo convencional" (2015, p. 82) ${ }^{12}$.

Al reducir la narración a eso que registra la cámara, casi siempre operada por Mirtahmasb, Panahi elimina la función de director, de la cual ha sido políticamente excluido. Sin embargo, aprovecha el forzoso tiempo de ocio para revisar sus películas anteriores y recuerda cómo durante la realización de El espejo y Sangre y oro, que sí pudo dirigir, también se topó con elementos (los actores, el velo femenino) que lo limitaron como agente. Las restricciones, impuestas o no por el exterior, se revelan como una característica del proceso creativo. Esta revisión pone nuevamente en escena lo digital, pues la hace por medio de las copias en formato DVD - es decir, "digital video disc"- de los filmes, que repasa en el televisor de la sala de su casa.

Las facilidades técnicas que ofrecen las cámaras digitales, así como la cotidiana omnipresencia de estas, permiten a Panahi construir el ardid con el que se reinventa como generador de sentido pese a la prohibición impuesta por el Gobierno. Este último no es encarnado por ningún personaje en Este no es un filme y Taxi, y solo se manifiesta a través del detalle de sus circunstancias judiciales y de sus clientes. En la segunda película, aparece además a través de la asignación escolar de la sobrina, la cual pone en evidencia la manera cómo la estructura de poder norma las prácticas discursivas. La niña dice tener que filmar una película distribuible, esto es, una que presente la realidad, pero que cumpla con una serie de reglas, como respetar el velo islámico, no abordar cuestiones políticas y económicas o evitar la violencia y el "realismo sórdido"13. El origen de estas expectativas puede rastrearse hasta el ayatolá Ruhollah Jomeini, líder de la revolución islámica de 1979, quien señaló que el cine, antes un aliado de la occidentalización (y el hundimiento) de la sociedad iraní, podía ser una herramienta para educar al pueblo (Zeydabadi-Nejad, 2007, p. 379).

12 "[...] the intrusion of the filmmaking process into the filmed reality destabilizes claims to conventional realism”.

13 Pese a las diferencias geopolíticas entre EE. UU. e Irán, históricamente el cine de Hollywood (el MRI hegemónico) también ha seguido normas (algunas explícitas, como el denominado código Hays) respecto a la diferencia sexual, la caracterización sociocultural de protagonistas y antagonistas, o el tratamiento de contradicciones políticas y económicas que pueden homologarse a las del "filme distribuible" descrito por este personaje de Taxi. 
Un filme distribuible es, claramente, una producción que se adecúa a un modo de representación - en este caso normado por un Gobierno teocrático-, en el que la impresión de realidad se impone sobre la realidad misma, de allí la prohibición del "realismo sórdido". Panahi se opone a esta realidad embellecida o disimulada, y la desenmascara a través de la presentación sin filtros de la sociedad iraní (El círculo, Sangre y oro), y de la problematización del dispositivo cinematográfico en El espejo. En Este no es el filme y Taxi, lo hace además eludiendo la censura a través del subterfugio de un dispositivo digital que actúa sin su participación como director o guionista, y genera un relato a partir de las múltiples cámaras que de todas maneras pueblan la cotidianidad mediática y el espontáneo fluir de la realidad.

\section{Conclusiones}

En Taxi, el ardid derivado de las condiciones del dispositivo digital, según el cuales es el automóvil o las cámaras operadas por sus pasajeros las que narran, y no el director condenado a no dirigir, es apuntalado por la poderosa metáfora con que cierra la película (1:19:30-1:21:00): mientras Panahi y su sobrina salen del automóvil en busca de dos clientes que dejaron olvidada una cartera, un par de jóvenes llegan en motocicleta y lo abren para robar. Los muchachos consiguen sustraer la cámara (al desconectarla, la pantalla queda en negro), pero no logran llevarse el sistema de sonido (de manera que la banda sonora continúa sin imagen) ni la tarjeta de memoria (es por eso por lo que el filme sobrevive). Panahi descompone el dispositivo digital en sus partes (imagen, sonido, memoria), y al hacerlo muestra una sociedad pobre y violenta que le despoja de medios para mirar y contar (la cámara que le roban), pero no ha podido despojarle de su memoria (y las imágenes que la componen).

Como ha sido señalado, esta película y la anterior, Este no es un filme, brindan continuidad a las que han sido, hasta hoy, las principales inquietudes de la obra de Jafar Panahi: los problemas de la sociedad iraní, en particular la pobreza y la discriminación de la mujer, y el dispositivo cinematográfico. Lo hace ahora pese a la prohibición de dirigir impuesta por el régimen de los ayatolás y gracias a las facilidades que ofrecen las nuevas tecnologías. Hay entonces una remediación digital de las operaciones hechas anteriormente en película como El espejo, dedicada 
ya al dispositivo cinematográfico, o Sangre y oro, sobre la correlación entre pobreza y violencia.

En las películas abordadas, Este no es un filme y Taxi, pero también en El espejo, el director iraní invita a pensar en un filme que "se hace solo", según las condiciones de un dispositivo autónomo, que genera un relato sin la mediación de un director o narrador consciente, por la simple actividad de un artefacto (la cámara en el taxi), de un camarógrafo (quien, supuestamente, no tiene director que lo dirija) o la huida de una niña (quien no sabe que es filmada). En los dos largometrajes más recientes, lo hace poniendo en escena lo plural y lo fragmentario de las narraciones digitales contemporáneas: las cámaras, múltiples y omnipresentes, que registran con un mínimo de intervención humana (como en los sistemas de monitoreo), o según decisiones que no son las de un narrador fílmico (como las integradas a los teléfonos celulares). Panahi nos sitúa así frente a regímenes de visión que extraen de la realidad imágenes en movimiento susceptibles de constituir historias, y nos recuerda nuestra condición simultánea de sujetos y objetos de registro audiovisual. La operación le permite además continuar con su cuestionamiento del dispositivo, desarrollado explícitamente en El Espejo, y afinado, gracias a los recursos que ofrece lo digital, en Este no es un filme y Taxi. Estos recursos ayudan también a continuar con un examen "sórdido" de la sociedad iraní, al tiempo que hace una denuncia de sus circunstancias personales (arresto domiciliario, prohibición de dirigir).

Las películas de Panahi muestran algunos de los rasgos del cine digital: unos de carácter técnico y operativo (dimensiones y portabilidad de las cámaras, almacenamiento), otros narrativo (fragmentación y dispersión de las perspectivas) y representacional (los rasgos de qué se considera realidad, como la espontaneidad de las tomas o del comportamiento de los individuos). Se prestan además para reflexionar sobre las narraciones en el límite entre la ficción y la realidad, o entre la ficción y el documental; esta es una problemática propia de la era digital, en la que se han popularizado las imágenes, pero también la desconfianza respecto a ellas.

Retomemos los que parecen los elementos más importantes de este artículo. En primer lugar, a partir del uso de diferentes cámaras digitales, Panahi continúa con el desenmascaramiento del dispositivo propio de los modos de representación institucionales; en Taxi, construye una suerte de narración polifónica, en la que diferentes personajes, o el mismo vehículo, son los agentes del registro audiovisual. En segundo lugar, esta dispersión 
de los agentes rompe la impresión de realidad que caracterizó los MRI durante el siglo xx, pero para construir otra: la de la realidad "capturada" en directo, azarosa y espontánea, sin la intermediación de directores y guionistas, o de un aparataje de producción. Sobre esto, hay que señalar que no es solamente posible gracias a las cada vez más pequeñas cámaras digitales, algunas en los teléfonos móviles, sino al hecho de que la multiplicación de operadores audiovisuales es ya parte de la cotidianidad. En tercer lugar, y siempre respecto al contexto mediático, los dos filmes ponen en evidencia y se sirven de la omnipresencia de la cámara: lo que hasta hace unas décadas era un recurso de voyeurs o para la vigilancia por parte del sistema hegemónico, se convierte en Panahi en una herramienta para la insurgencia. En cuarto lugar, y como se ha insistido a lo largo del texto, los elementos digitales incorporados al dispositivo cinematográfico en Este no es un filme (un apartamento) y Taxi (un vehículo) hacen posible la puesta en escena, pero también la condicionan, y determina la distancia de la mirada, la calidad de la imagen, la composición de los encuadres o los movimientos de la cámara (muchas veces, en las manos de los personajes). Finalmente, todo esto para desarrollar narraciones que son políticas, pues denuncian censura y violación de derechos humanos (Este no es un fllme), y pobreza y violencia (Taxi), a pesar de que, en principio, no tienen una voluntad detrás, sino que simplemente registran la realidad, tal cual. Sobre esto último: es justamente a través de este subterfugio, posible por lo digital, que Panahi finge respetar la prohibición impuesta por el Gobierno de los ayatolas.

\section{Referencias}

Albera, F., \& Tortajada, M. (2011). Le dispositif n'existe pas! En Ciné-dispositifs. Spectacles, cinéma, télévision, littérature (pp. 13-38). Lausanne: L'Âge de l'Homme.

Bolter, J. D. (2005). Transference and Transparency: Digital Technology and the Remediation of Cinema. Intermédialités : histoire et théorie des arts, des lettres et des techniques, (6), 13-26. doi: 10.7202/1005503ar

Bordwell, D., Staiger, J., \& Thompson, K. (1985). The Classical Hollywood Cinema. Film Style $\mathcal{E}^{\circ}$ Mode of Production to 1960. New York: Columbia University Press.

Brown, W. (2009). The drama of the digital: D.N. Rodowick, Garrett Stewart, and narrative cinema. New Review of Film and Television Studies, 7 (2), 225-236. doi: $10.1080 / 17400300902817000$

Casetti, F. (2011). Sutured Reality: Film, from Photographic to Digital. October, (138), 95-106. 
Cronk, J. (2015). Taxi by Jafar Panahi. Cinéaste, 40(4), 48-50. Recuperado de http:// www.jstor.org/stable/26356465

Deleuze, G. (1990). ¿Qué es un dispositivo?. En E. Balbier et. al (eds.), Michel Foucault, filósofo (pp. 155-163; Alberto L. Bixio, trad.). Barcelona: Gedisa.

Figgis, M. (2000). Timecode. Estados Unidos.

Foucault, M. (2001). Le jeu de Michel Foucault. En Dits et écrits, II. 1976-1988 (pp. 298-329). París: Gallimard.

Friedlander, J. (2015). Documentary REAL-ism: Catfish and This Is Not a Film. Cinémas : revue d'études cinématographiques, 26 (1), 69-91. doi:10.7202/1037002ar

Giraud, T. (2004). Le numérique impose-t-il un nouveau cinéma ?. Esprit, 6(305), 53-62. Recuperado de: http://www.jstor.org/stable/24249345

González-Requena, J. (2012). Clásico, manierista, postclásico. Los modos del relato en el cine de Hollywood. Valladolid: Castilla ediciones.

Kessler, F. (2003). La cinématographie comme dispositif (du) spectaculaire. Cinémas : revue d'études cinématographiques, 14 (1). doi:10.7202/008956ar

Kessler, F. (2011). Recadrages : pour une pragmatique historique du dispositif cinématographique. Recherches sémiotiques, 31 (1-2-3). doi:10.7202/1027438ar

Kiarostami, A. (2002). Dah (Ten). Irán: MK Productions.

Ortel, P. (2011). L' « effet-dispositif » dans le récit cinématographique. En F. Albera \& M. Tortajada (eds.). Ciné-dispositifs. Spectacles, cinéma, télévision, littérature (pp. 205-225). Lausanne: L'Âge de l'Homme.

Panahi, J. (1995). Badkonake sefid (El globo blanco). Irán.

Panahi, J. (1997). Ayneh (El Espejo). Iran: Rooz Film.

Panahi, J. (2000). Dayereh (El círculo). Iran: Jafar Panahi Film Productions.

Panahi, J. (2003). Talaye Sorkh (Sangre y oro). Irán.

Panahi, J. (2006). Offside (Fuera de juego). Irán.

Panahi, J., \& Mirtahmasb, M. (2011). In Film Nist (Este no es un filme). Irán: Jafar Panahi Film Productions.

Vertov, D. (2010a). Del cine-ojo al radio-ojo (extracto del ABC de los kinocs). En J. Romaguera i Ramió \& H. Alsina Thevenet (eds.), Textos y Manifiestos del Cine. Estética. Escuelas. Movimientos. Disciplinas. Innovaciones (pp. 30-36). Madrid:

Cátedra.

Vertov, D. (2010b). El kino-pravda. En J. Romaguera i Ramió \& H. Alsina Thevenet, Textos y Manifiestos del Cine. Estética. Escuelas. Movimientos. Disciplinas. Innovaciones (pp. 45-50). Madrid: Cátedra.

Zeydabadi-Nejad, S. (2007). Iranian Intellectuals and Contact with the West: The Case of Iranian Cinema. British Journal of Middle Eastern Studies, 34 (3), 375398. Recuperado de http://www.jstor.org/stable/20455536. 